\title{
Agronomic Factors Affecting the Potential of Sorghum as a Feedstock for Bioethanol Production in the Kanto Region, Japan
}

\author{
Shoko Ishikawa ${ }^{1, *}$, Takayuki Tsukamoto ${ }^{2}$, Hitoshi Kato ${ }^{3}$, Kazuto Shigeta ${ }^{1}$ and \\ Ken-ichi Yakushido ${ }^{4}$ \\ 1 Division of Crop Production Systems, Central Region Agricultural Research Center, NARO, \\ Tsukuba 305-8666, Japan; kazuto@affrc.go.jp \\ 2 Department of Farm Labor and Environmental Engineering, Institute of Agricultural Machinery, NARO, \\ Saitama, 331-8537, Japan; tsukamot@affrc.go.jp \\ 3 Division of Lowland Farming, Central Region Agricultural Research Center, NARO, Joetsu 943-0193, Japan; \\ katojin@affrc.go.jp \\ 4 Division of Livestock and Grassland Research, Kyushu Okinawa Agricultural Research Center, NARO, \\ Koshi 861-1192, Japan; yakushi@affrc.go.jp \\ * Correspondence: shokoish@affrc.go.jp; Tel.: +81-29-838-8522
}

Academic Editor: Michael Wachendorf

Received: 9 May 2017; Accepted: 27 May 2017; Published: 2 June 2017

\begin{abstract}
In the Kanto region in Japan, the possibilities of running a bio-ethanol plant from rice straw has been assessed and sorghum production has been considered as a necessary part of the system. Two field experiments were conducted in 2012 and 2013 at the NARO_Agricultural Research Center in Tsukuba, Ibaraki to estimate yielding ability of sorghum in the Kanto region. Two cultivars of sweet sorghum and one of grain sorghum were sown using a pneumatic seeder. Above-ground dry matter (DM) yield ranged from 1.03 to $1.82 \mathrm{~kg} \mathrm{~m}^{-2}$ for the sorgo type cultivars and from 0.70 to $1.18 \mathrm{~kg} \mathrm{~m}^{-2}$ for the grain type cultivar. The observed yields were lower than the simulated potential yields, i.e., 1.61 to $2.66 \mathrm{~kg} \mathrm{~m}^{-2}$, indicating that biomass production was restricted in this study. Stem brix values for the sweet sorghum cultivars were generally low (3.3-16.2\%) compared with the values reported in the literature. It appears that there is still room to improve the field management of sorghum to minimize the gap between the potential and actual production observed in these experiments.
\end{abstract}

Keywords: bioethanol; feedstock; the Kanto region; potential yield; sweet sorghum

\section{Introduction}

Unlike the southwest islands where sugarcane is almost exclusively expected to play a key role as a feedstock for bio-ethanol plants [1], rice straw is likely to be a major feedstock in the Kanto region [2,3]. Effective utilization of lignocellulosic biomass has been attempted by many researchers at both laboratory [4,5] and plant scales [6]. Issues of cost relative to those of fossil fuel are probably the major challenge to commercial implementation, i.e., construction and management of an actual plant. Cost aside, handling of by-products would arise as another major issue to be solved. Supposing an ethanol plant that has the capacity to produce $15,000 \mathrm{~kL}$ of ethanol annually, a similar capacity to a plant that used to work in Hokkaido (Hokkaido bioethanol, Co., Ltd.), 150,000-300,000 kL of vinasse could be generated, assuming the ratio of 10-20 to the ethanol [7]. Being stripped of energy in the form of ethanol, vinasse still contains organic matter and therefore has a high chemical oxidative demand (COD). Releasing it casually, for example, into surface waters would not only be damaging to the environment but also be regarded as a waste of valuable energy and nutrients. In Brazil, the practice of applying sugarcane vinasse to fields to replace mineral fertilizers has been accused of causing 
environmental problems including odor and possible emissions of greenhouse gasses where anaerobic digestion is suggested as a possible remedy [8]. An ethanol plant in the Kanto region with the major feedstocks being rice straw, vinasse could be applied to paddies but only at a particular time of year when rice needs nutrients for growth, while vinasse is generated in the ethanol plants all year round or close to it. It would therefore be necessary to develop cropping systems, apart from paddies, that could receive vinasse at various timings throughout the year. It would be preferable if the constituent crops could contribute to the operation of the ethanol plant as feedstocks when necessary. It would also be beneficial to incorporate double purpose cropping like the one reported on wheat [9] which employs a chance-seeking way of production, i.e., growers can change the usage of the standing crop in the field according to the prevailing meteorological and socioeconomic conditions, within a newly developed cropping system. It is known that sugarcane mills in Brazil have been altering the ratio of production of ethanol to sugar according to the demand [10], this flexibility within the biofuel industry is clearly advantageous where competition for fertile cropland for food production is concerned [11].

Sorghum has long been used as staple, sugar and feed crop in arid and semi-arid areas prone to drought [12,13], although its use especially for sugar [14] and as feed [15] has spread to temperate regions. Sorghum has been widely recognized as a potential source of biofuel since the era of oil shock in the 1970s [16-18] due to its ability to produce high biomass and sugars from a relatively short growing period. The recent upsurge in the number of biomass studies could largely be attributable to the adoption of the Kyoto protocol in 1997 [19], which was concerned in part with the increasing greenhouse gas emissions caused by anthropological activities. Recent field studies conducted at relatively high latitudes have generally focused on the characterization of sorghum as a feedstock and on estimating the amount of producible ethanol [20-22]. In addition, some studies have looked at the effects of planting date and/or harvest date on sorghum biomass yield in the context of energy production [23-26].

In Japan, reflecting an increased demand by growers to use sorghum as a feed crop after the 1950s [27], a substantial number of studies can be found in the literature on this crop [28,29]. However, the number of domestic studies clearly placing sorghum as a feedstock for biomass-energy industry is rather limited. Hoshikawa $[16,17]$ was probably among the first to have recognized the potential for sorghum to be a biomass crop in the country. He and his group have conducted extensive work particularly focusing on sweet sorghum, the type that accumulates sugar in stem, in the Tohoku region [17,18,30,31]. Wu et al. [32] has reported above-ground DM yield of a grain sorghum variety (12.85 Mg ha ${ }^{-1}$ ) and of two sweet sorghum varieties (22.75 $\mathrm{Mg} \mathrm{ha}^{-1}$ and $23.66 \mathrm{Mg} \mathrm{ha}^{-1}$ ) planted in Minamiminowa located in the Chubu region. In the Kanto region, Yasui et al. [33,34], in a series of studies conducted under the project named "biomass transmutation plan" funded by MAFF, investigated stem constituents, especially sugars of sorghum sown on different planting dates. However, they did not investigate the biomass yielding ability of sorghum. Inuyama et al. [27] obtained stem fresh weights in the range of $33.7-44.8 \mathrm{Mg} \mathrm{ha}^{-1}$ for three sorghum cultivars planted on 20 May. The DM yield, however, was unfortunately not clear from their study.

The objective of the present study was to estimate the potential biomass yield of sorghum in upland cropping systems in the Kanto region for different planting dates with the aid of simple simulation techniques. Estimation of potential biomass yield was used to help identify the factors that could possibly hinder successful sorghum production in the target region as well as proposing necessary production techniques to overcome these factors. Establishing and running a biomass energy system requires cooperation among stakeholders of different interests and disciplines. It is hoped that the present study will provide an agronomic perspective on this issue so that participants and stakeholders of present and future biomass energy projects can have information about feedstock crops (e.g., sorghum) in terms of climate and crop management systems. 


\section{Materials and Methods}

\subsection{Field Experiments}

A field experiment was conducted in a field at the NARO-Agricultural Research Center (the predecessor of the Central Region Agricultural Research Center, NARO) $\left(36^{\circ} 02^{\prime} \mathrm{N}, 140^{\circ} 10^{\prime} \mathrm{E}\right)(3-1-1$, Kannondai, Tsukuba, Ibaraki, 305-8666, Japan) in 2012 and 2013. pH ( $\left.\mathrm{H}_{2} \mathrm{O}\right)$, total nitrogen, available phosphoric acid, exchangeable potassium and humus content in the soil sampled in 2013 were 6.5, $0.35 \%, 1.5 \mathrm{mg} / 100 \mathrm{~g}, 65.3 \mathrm{mg} / 100 \mathrm{~g}$ and $6.8 \%$, respectively. Seeds of three sorghum cultivars, SIL05 (NARO), high sugar sorgo (FS501) (Snow brand seed, Sapporo) and meter sorgo (8080) (TAKII \& Co., Ltd., Kyoto, Japan) were sown using a pneumatic seeder (AS404-HW, KUBOTA). SIL05 and FS501 are sweet sorghum, while 8080 grain sorghum. Sowing dates and seed rates are presented in Table 1. The target seed rates were 20, 10, and 10 for SIL05, FS501 and 8080, respectively, depending on the size of the seeds of each cultivar. Furrow spacing was $0.7 \mathrm{~m}$. Nitrogen, phosphorus and potassium of a high analysis compound fertilizer $\left(\mathrm{N}, \mathrm{P}_{2} \mathrm{O}_{5}, \mathrm{~K}_{2} \mathrm{O} ; 14 \%, 14 \%, 14 \%\right)$ were set to be applied as side dressing at sowing at the rate of $12 \mathrm{~g} \mathrm{~m}^{-2}$ (Table 2). A split-plot design with two replicates was applied with the main plot being sowing date. The size of each plot was $5.6 \mathrm{~m}$ by $48 \mathrm{~m}$. After harvesting and the removal of the above-ground parts of the sorghum crop, the field was planted with winter crops mostly oat in 2012 and rye in 2013.

Table 1. Seed rates over two seasons.

\begin{tabular}{cccccc}
\hline & \multicolumn{5}{c}{ Seed Rate $\left(\mathbf{m}^{-\mathbf{2}}\right)$} \\
\cline { 2 - 6 } Cultivar & \multicolumn{3}{c}{ 2012 } & \multicolumn{3}{c}{ 2013 } \\
\cline { 2 - 6 } & 17 May & 7 June & 26 June & 13 May & 28 May \\
\hline SIL05 & 21.7 & 26.5 & 34.2 & 32.4 & 32.5 \\
FS501 & 10.7 & 10.8 & 15.9 & 16.1 & 14.8 \\
8080 & 11.4 & 10.7 & 16.5 & 16.5 & 13.3 \\
\hline
\end{tabular}

Table 2. Fertilization rates $\left(\mathrm{g} \mathrm{m}^{-2}\right)$ applied over two seasons.

\begin{tabular}{ccccc}
\hline Year & Sowing Date & $\mathbf{N}$ & $\mathbf{P}_{\mathbf{2}} \mathbf{O}_{\mathbf{5}}$ & $\mathbf{K}_{\mathbf{2}} \mathbf{O}$ \\
\hline \multirow{3}{*}{2012} & 17 May & 12.2 & 12.2 & 12.2 \\
& 7 June & 11.6 & 11.6 & 11.6 \\
& 26 June & 9.3 & 9.3 & 9.3 \\
\hline \multirow{2}{*}{2013} & 13 May & 10.7 & 10.7 & 10.7 \\
& 28 May & 10.6 & 10.6 & 10.6 \\
\hline
\end{tabular}

\subsection{Sampling and Analysis}

Above-ground biomass of known area, i.e., $1.4 \mathrm{~m}^{2}$ (two rows), was harvested every two weeks until harvest (Table 3). In 2013, samples, except for harvest, were taken from an area of $0.7 \mathrm{~m}^{2}$ (a single row) instead of two rows, as it was found difficult to take hold of two rows of plants showing average growth, i.e., plants of either row tended to show a poor growth. For the sampled plants, height was measured and effective tiller number counted. A part of each sample consisting of 2-3 plants (sub-sample A) was taken, separated to each organ, i.e., leaf blade, stem and leaf sheath and then its fresh weight was determined. Sub-sample A was dried at $80^{\circ} \mathrm{C}$ in an oven to constant weight and DM weight was then determined. Another part of each sample, the size of which was similar to that of sub-sample A (sub-sample B) was taken to determine leaf area index (LAI) using an automatic area meter, AAM-8 (Hayashi Denko co Ltd., Tokyo, Japan). At the same time, weeds were also sampled from the same area where sorghum plants were sampled and then their DM weight determined by the same method used for the sorghum samples. After heading, the brix value of stems was measured using a ref brix, PR-101 $\alpha$ (ATAGO, Tokyo, Japan). 
Table 3. Sampling dates and days after sowing (DAS) over two cropping seasons.

\begin{tabular}{|c|c|c|c|c|c|c|c|c|c|c|}
\hline \multirow{3}{*}{$\begin{array}{c}\text { Year } \\
\text { Sowing (Date) } \\
\text { Sampling }\end{array}$} & \multicolumn{6}{|c|}{2012} & \multicolumn{4}{|c|}{2013} \\
\hline & \multicolumn{2}{|c|}{ Early (17 May) } & \multicolumn{2}{|c|}{ Medium (7 June) } & \multicolumn{2}{|c|}{ Late (26 June) } & \multicolumn{2}{|c|}{ Early (13 May) } & \multicolumn{2}{|c|}{ Medium (28 May) } \\
\hline & Date & DAS & Date & DAS & Date & DAS & Date & DAS & Date & DAS \\
\hline $1 \mathrm{st}$ & 12 June & 26 & 3 July & 26 & 26 July & 30 & 18 June & 36 & 25 June & 28 \\
\hline 2 nd & 26 June & 40 & 17 July & 40 & 8 August & 43 & 2 July & 50 & 9 July & 42 \\
\hline $3 r d$ & 10 July & 54 & 31 July & 54 & 22 August & 57 & 16 July & 64 & 22 July & 55 \\
\hline 4th & 24 July & 68 & 14 August & 68 & 5 September & 71 & 30 July & 78 & 6 August & 70 \\
\hline 5 th & 7 August & 82 & 28 August & 82 & 19 September & 85 & 13 August & 92 & 20 August & 84 \\
\hline 6th & 21 August & 96 & 11 September & 96 & 3 October * & 99 & 26 August & 105 & 3 September & 98 \\
\hline 7th & 4 September & 110 & 25 September * & 110 & & & 9 September * & 119 & 17 September * & 112 \\
\hline 8th & 12 September * & 118 & & & & & & & & \\
\hline
\end{tabular}

* Last sampling is referred to harvest. 


\subsection{Statistical Analysis and Simulation}

Analysis of variance (ANOVA) and the following multiple comparisons by Bonferroni's test as well as regression analysis were performed using an SPSS 13.0 (IBM Japan, Ltd., Tokyo, Japan). Intercepted radiation was calculated on a daily basis from emergence to maturity according to Monsi and Saeki [35]. Extinction coefficients for sorghum of 0.37 and 0.60 were employed from the literature [36,37]. Daily gross assimilation (Equation (1)) and growth (Equation (2)) and maintenance respirations (Equation (3)) were calculated using the following equations according to Lövenstein et al. [38]. Assimilation efficiency (Ea) and reflection coefficient $\left(\mathrm{p}_{\mathrm{c}}\right)$ were fixed as 9, i.e., a typical value for $\mathrm{C} 4$ crops, and 0.08 respectively. A temperature correction coefficient (TC) was calculated for each day by applying the average temperature on the day. Although the experiments were conducted on two replicates, one replicate that was considered to be an outlier was omitted from calculations when values of the two replicates differed to a large degree, i.e., the value of one replicate was smaller than that of the other by more than $30 \%$.

$$
\begin{gathered}
\mathrm{At}=\mathrm{Ea} \times\left(1-\mathrm{p}_{\mathrm{c}}\right) \times \mathrm{It} \times\{1-\exp (-\mathrm{k} \times \mathrm{LAIt})\} \\
\mathrm{MRt}=\mathrm{TC} \times \sum(\mathrm{A} 0+\mathrm{A} 1+\mathrm{A} 2+\ldots+\mathrm{At}) \\
\mathrm{GRt}=0.3 \times(\mathrm{At}-\mathrm{MRt})
\end{gathered}
$$

At: daily crop assimilation at day $\mathrm{t}\left[\mathrm{kg} \mathrm{CO}_{2} \mathrm{ha}^{-1}\right.$ day $\left.^{-1}\right]$ (t: day number)

Ea: assimilation efficiency $\left[\mathrm{kg} \mathrm{CO}_{2} \mathrm{~J}^{-1}\right]$

It: Incident PAR at day t $\left[\mathrm{J} \mathrm{ha}^{-1}\right.$ day $\left.^{-1}\right]$

$\mathrm{p}_{\mathrm{c}}$ : crop reflection coefficient

k: extinction coefficient

LAIt: green leaf area index at day $t$

MRt: maintenance respiration at day $t$

TC: temperature correction coefficient

GRt: growth respiration at day $\mathrm{t}$

\section{Results}

\subsection{Weather}

Mean daily temperature, total rainfall and total solar radiation during the experiments are

\begin{tabular}{|c|c|c|c|c|c|c|}
\hline \multirow[b]{2}{*}{ Month } & \multicolumn{3}{|c|}{2012} & \multicolumn{3}{|c|}{2013} \\
\hline & $\begin{array}{c}\text { Temperature } \\
\left({ }^{\circ} \mathrm{C}\right)\end{array}$ & $\begin{array}{l}\text { Rainfall } \\
\text { (mm) }\end{array}$ & $\begin{array}{c}\text { Solar Radiation } \\
\text { (MJ) }\end{array}$ & $\begin{array}{c}\text { Temperature } \\
\left({ }^{\circ} \mathrm{C}\right)\end{array}$ & Rainfall (mm) & $\begin{array}{c}\text { Solar Radiation } \\
\text { (MJ) }\end{array}$ \\
\hline May & 18.0 & 194 & 597 & 17.5 & 49 & 686 \\
\hline June & 19.7 & 177 & 565 & 21.1 & 110 & 496 \\
\hline July & 25.2 & 115 & 593 & 25.3 & 43 & 586 \\
\hline August & 27.6 & 11 & 663 & 27.5 & 61 & 615 \\
\hline September & 24.5 & 136 & 449 & 23.2 & 154 & 459 \\
\hline October & 17.3 & 131 & 375 & 18.1 & 429 & 311 \\
\hline Mean & 22.1 & 127 & 540 & 22.1 & 141 & 525 \\
\hline
\end{tabular}
presented in Table 4. There was a long dry spell of nearly 50 days in July and August 2013.

Table 4. Mean temperature, total rainfall and total solar radiation over two cropping seasons.

\subsection{Leaf Area Index (LAI)}

LAI observations made at the time of samplings were linearly interpolated (Figure 1). In 2012, the peak of LAI was in the range of 5-6, while it was in that of 8-11 in 2013. LAI tended to decrease very quickly in 2013 due to the severe infestation by aphids. Similarly, to the process of simulation, one 
replicate out of the two was omitted from calculations when values of two replicates differed to a large degree, i.e., the value of one replicate was smaller than that of the other by more than $30 \%$, and one was considered as an outlier. The interpolated LAI data obtained here were then used to estimate light interception and biomass yield in the process of simulation.
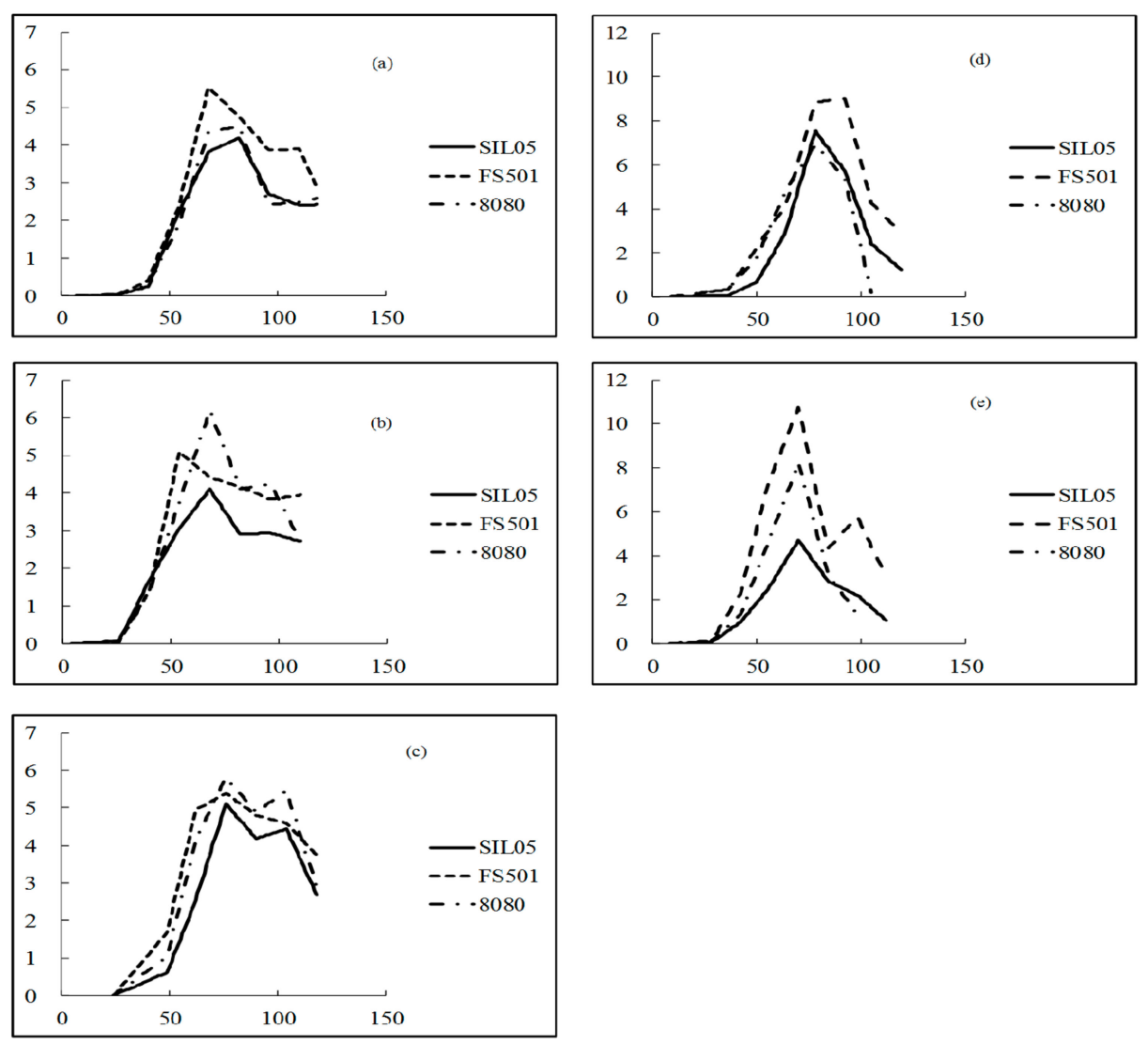

Figure 1. Interpolation of Leaf Area Index (LAI) sown: (a) Early (2012); (b) Medium (2012); (c) Late (2012); (d) Early (2013); and (e) Medium (2013). X axis: days after sowing (DAS); Y axis: LAI.

\subsection{DM Yield and Brix}

Height, LAI, effective tiller number, DM yield of different organs, DM content of above-ground part and stem brix are presented in Table 5. Interactions were observed with panicle DM yield, DM content and stem brix. As to panicle DM yield, significant interactions between cultivar $\times$ year and sowing $\times$ year were observed. In the former interaction, it was greater in 2012 than in 2013 for FS501 and 8080 while no significant difference between two years was recognized for SIL05. In the latter interaction, greater panicle DM yield was observed for early sowing than for medium sowing in 2013, while there was no difference between the two sowing timings in 2012. In DM content, no difference was observed between SIL05 and FS501 for early sowing, while for medium sowing, DM content was higher for SIL05 than FS501. As to stem brix, there was no difference between two years for medium sowing, while a greater value was observed in 2012 than in 2013 for early sowing. There was no difference between SIL05 and FS501 for early sowing, while stem brix values were significantly higher for SIL05 than for FS501 for medium sowing. Effects of sowing dates were hardly seen except for height where greater height was associated with early sowing. FS501 showed greater LAI than SIL05 and 8080. Pearson's correlation analysis revealed that stem brix was negatively correlated with leaf DM yield and panicle DM yield (Table 6) and it was positively correlated with stem DM yield and especially stem DM content. 
Table 5. Height, leaf area index (LAI), effective tiller, dry matter (DM) yield, DM content and brix of sorghum at harvest.

\begin{tabular}{|c|c|c|c|c|c|c|c|c|c|c|c|}
\hline \multirow[b]{2}{*}{ Year } & \multirow[b]{2}{*}{ Sowing } & \multirow[b]{2}{*}{ Cultivar } & \multirow[b]{2}{*}{ Height (cm) } & \multirow[b]{2}{*}{ LAI } & \multirow[b]{2}{*}{ Efftiller $\left(m^{-2}\right)$} & \multicolumn{4}{|c|}{ DM Yield } & \multirow{2}{*}{$\begin{array}{c}\text { DM Content } \\
\text { Above-Ground } \\
\text { (\%) }\end{array}$} & \multirow[b]{2}{*}{ Brix $(\%)$} \\
\hline & & & & & & $\begin{array}{c}\mathrm{LS}+\text { Stem } \\
\left(\mathrm{kg} \cdot \mathrm{m}^{-2}\right)\end{array}$ & $\begin{array}{c}\mathrm{LB} \\
\left(\mathrm{kg} \cdot \mathrm{m}^{-2}\right)\end{array}$ & $\begin{array}{c}\text { Panicle } \\
\left(\mathrm{kg} \cdot \mathrm{m}^{-2}\right)\end{array}$ & $\begin{array}{l}\text { Above-Ground } \\
\left(\mathrm{kg} \cdot \mathrm{m}^{-2}\right)\end{array}$ & & \\
\hline \multirow{9}{*}{2012} & \multirow{3}{*}{ Early } & SIL05 & 325 & 2.42 & 13.6 & 1.31 & 0.38 & 0.12 & 1.82 & 24.1 & 12.6 \\
\hline & & FS501 & 318 & 2.89 & 11.4 & 1.08 & 0.42 & 0.11 & 1.61 & 25.2 & 13.7 \\
\hline & & 8080 & 151 & 2.59 & 12.9 & 0.35 & 0.47 & 0.37 & 1.18 & 31.0 & \\
\hline & \multirow{3}{*}{ Medium } & SIL05 & 269 & 2.09 & 14.3 & 0.88 & 0.25 & 0.12 & 1.24 & 24.9 & 16.2 \\
\hline & & FS501 & 308 & 3.94 & 12.9 & 0.97 & 0.47 & 0.33 & 1.77 & 22.5 & 6.1 \\
\hline & & 8080 & 141 & 1.95 & 10.8 & 0.22 & 0.44 & 0.46 & 1.12 & 25.9 & \\
\hline & \multirow{3}{*}{ Late } & SIL05 & 286 & 2.58 & 15.7 & 0.78 & 0.28 & 0.08 & 1.13 & 20.8 & 13.0 \\
\hline & & FS501 & 337 & 3.74 & 12.9 & 0.79 & 0.42 & 0.19 & 1.40 & 18.6 & 5.2 \\
\hline & & 8080 & 146 & 2.90 & 15.0 & 0.20 & 0.38 & 0.46 & 1.04 & 27.6 & \\
\hline \multirow{6}{*}{2013} & \multirow{3}{*}{ Early } & SIL05 & 309 & 1.25 & 11.4 & 0.64 & 0.30 & 0.10 & 1.04 & 17.8 & 5.3 \\
\hline & & FS501 & 329 & 2.92 & 15.0 & 0.92 & 0.52 & 0.12 & 1.56 & 17.6 & 3.3 \\
\hline & & 8080 & 151 & 0.19 & 12.9 & 0.21 & 0.42 & 0.23 & 0.86 & 25.8 & \\
\hline & \multirow{3}{*}{ Medium } & SIL05 & 284 & 1.07 & 16.4 & 0.76 & 0.21 & 0.05 & 1.0 & 21.3 & 9.6 \\
\hline & & FS501 & 276 & 3.06 & 11.5 & 0.77 & 0.39 & 0.05 & 31.2 & 16.0 & 5.8 \\
\hline & & 8080 & 131 & 1.36 & 15.0 & 0.15 & 0.46 & 0.08 & 20.70 & 22.9 & \\
\hline Factor & $\mathrm{df}$ & df (Brix) & & & & & & & & & \\
\hline Year (Y) & 1 & 1 & & & & & & & & & \\
\hline Sowing (S) & 2 & 2 & ns & $* *$ & ns & * & ns & $* * *$ & * & $* * *$ & $* * *$ \\
\hline Cultivar (C) & 2 & 1 & * & ns & ns & ns & ns & ns & ns & $* *$ & ns \\
\hline$Y * S$ & 2 & 2 & $* * *$ & $* * *$ & ns & $* * *$ & $* *$ & $* * *$ & $*$ & $* * *$ & $* *$ \\
\hline$Y * C$ & 2 & 1 & ns & ns & ns & ns & ns & $* *$ & ns & ns & * \\
\hline$S * C$ & 4 & 2 & ns & ns & ns & ns & ns & $*$ & ns & ns & ns \\
\hline Block & 1 & 1 & ns & ns & ns & ns & ns & ns & ns & * & * \\
\hline Residual & 15 & 9 & & & & & & & & & \\
\hline Total & 29 & 19 & & & & & & & & & \\
\hline
\end{tabular}


Table 6. Pearson's correlation analysis between traits over two seasons.

\begin{tabular}{ccccc}
\hline & Leaf Dry Matter (DM) Yield & Panicle DM Yield & Stem DM Content & Stem Brix \\
\hline Stem DM yield & NS & $-0.41^{*}$ & $0.56^{* *}$ & $0.44^{*}$ \\
Leaf DM yield & & $0.38^{*}$ & NS & $-0.45^{*}$ \\
Panicle DM yield & & & NS & $0.46^{*}$ \\
Stem DM content & & & $0.86^{* *}$ \\
\hline
\end{tabular}

* Significant at $0.05 ; *$ Significant at 0.01 .

\subsection{Estimation of Radiation Use Efficiency (RUE)}

RUE was estimated by plotting above-ground DM yield against intercepted radiation (Figure 2a,b). Radiation intercepted by the sorghum canopy was simulated from daily solar radiation using an analogue of Beer's law [35,39] for each cultivar in each season. RUE is presented in Table 7. A light extinction coefficient (k) of 0.37 (Figure 2a,b and Table 7) and 0.60 (Table 7) was employed from the literature [36,37]. Greater RUE values were estimated by $13.8-24.4 \%$ when a light extinction coefficient of 0.37 was employed compared to 0.60 .

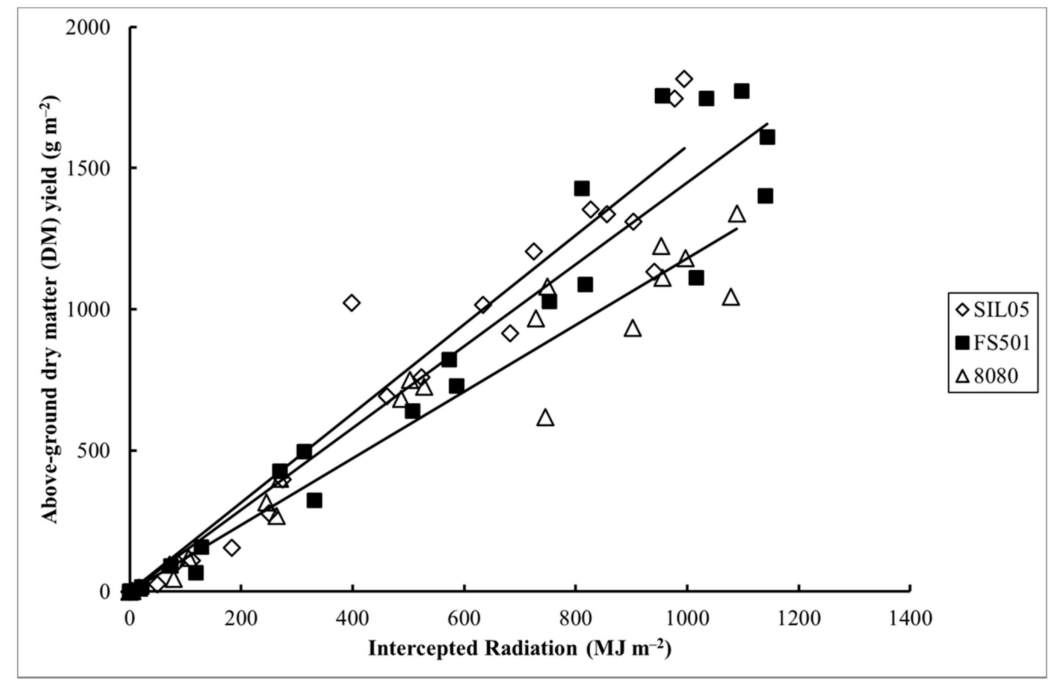

(a)

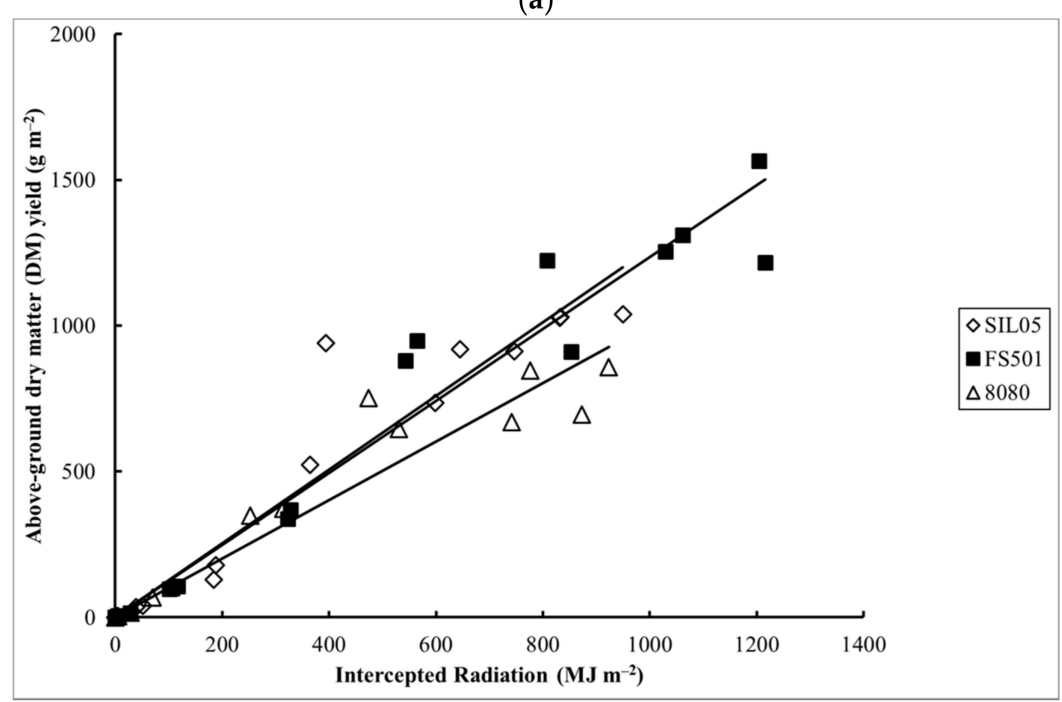

(b)

Figure 2. (a) The relationship between intercepted radiation and above-ground dry matter (DM) yield in 2012. (b) The relationship between intercepted radiation and above-ground DM yield in 2013. 
Table 7. Results of regression analysis between interpreted radiation and biomass yield.

\begin{tabular}{|c|c|c|c|c|c|c|}
\hline \multirow{2}{*}{ Year } & \multirow{2}{*}{ k } & \multirow{2}{*}{ Cultivar } & \multirow{2}{*}{$p$} & \multirow{2}{*}{$\mathbf{R}^{2}$} & \multicolumn{2}{|c|}{ Coefficient (RUE) } \\
\hline & & & & & $p$ & $\mathrm{~g} \mathrm{MJ}^{-1}$ \\
\hline \multirow{6}{*}{2012} & \multirow{3}{*}{0.37} & SIL05 & $<0.001$ & 0.97 & $<0.001$ & 1.58 \\
\hline & & FS501 & $<0.001$ & 0.97 & $<0.001$ & 1.45 \\
\hline & & 8080 & $<0.001$ & 0.98 & $<0.001$ & 1.18 \\
\hline & \multirow{3}{*}{0.60} & SIL05 & $<0.001$ & 0.97 & $<0.001$ & 1.27 \\
\hline & & FS501 & $<0.001$ & 0.97 & $<0.001$ & 1.21 \\
\hline & & 8080 & $<0.001$ & 0.98 & $<0.001$ & 0.98 \\
\hline \multirow{6}{*}{2013} & \multirow{3}{*}{0.37} & SIL05 & $<0.001$ & 0.96 & $<0.001$ & 1.26 \\
\hline & & FS501 & $<0.001$ & 0.98 & $<0.001$ & 1.23 \\
\hline & & 8080 & $<0.001$ & 0.96 & $<0.001$ & 1.01 \\
\hline & \multirow{3}{*}{0.60} & SIL05 & $<0.001$ & 0.96 & $<0.001$ & 1.03 \\
\hline & & FS501 & $<0.001$ & 0.98 & $<0.001$ & 1.08 \\
\hline & & 8080 & $<0.001$ & 0.96 & $<0.001$ & 0.85 \\
\hline
\end{tabular}

\subsection{Estimation of Biomass Yield}

Estimated daily assimilation and accumulated assimilation, i.e., yield, were presented as an example of the simulation for the data set of SIL05 sown early in 2012 (Figure 3a,b). The remaining results are presented in Table 8 . Net assimilation of FS501 exceeded $20 \mathrm{Mg} \mathrm{ha}^{-1}$ for all sowing dates in two years, while that of SIL05 were below $20 \mathrm{Mg} \mathrm{ha}^{-1}$ for 5 simulation sets out of 10 (Table 8). The simulated results were plotted against the observed biomass yield (Figure 4). The yield level obtained in the present study was found below the estimated potential (region B in Figure 4) except for in a few cases (region A in Figure 4). Another attempt was made to estimate the potential biomass production of sorghum at different locations from RUE and Water Use Efficiency (WUE) (Table 9). RUE of $1.4 \mathrm{~g} \mathrm{MJ}^{-1}$ and WUE of $5.0 \mathrm{~g} \mathrm{~kg}^{-1}$ were assumed following Narayanan et al. [40]. In contrast to USA, biomass production was greater when estimated from rainfall than from radiation in most of the locations in Japan except for Takamatsu, which is known for its dry summers, and Tsukuba (Kannondai) in 2012 and 2013, where the present study was conducted.

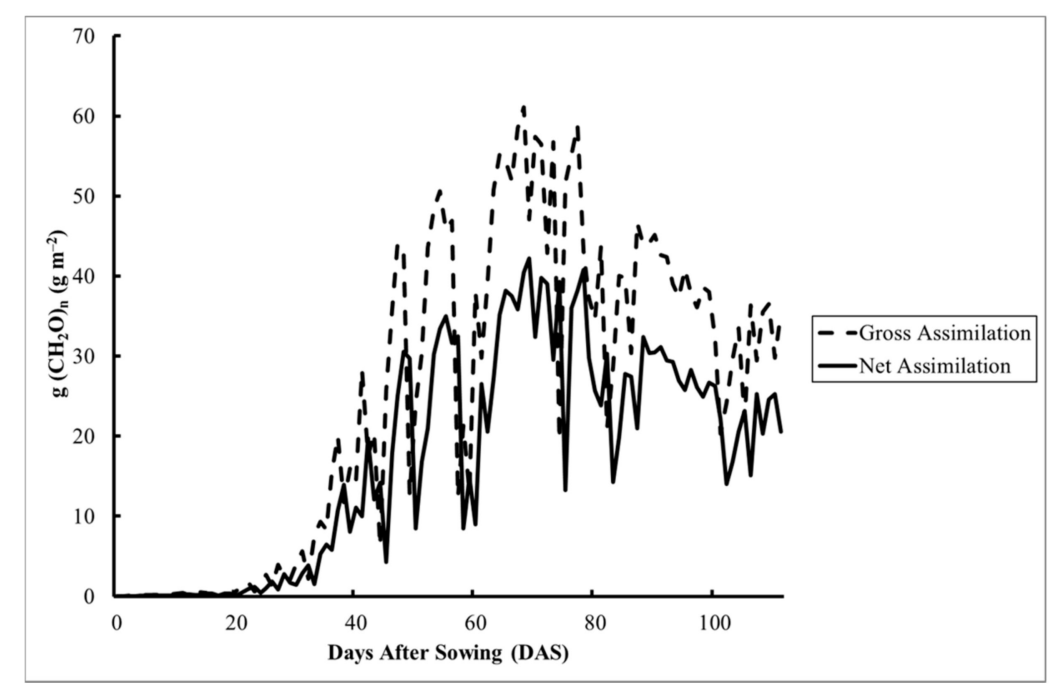

(a)

Figure 3. Cont. 


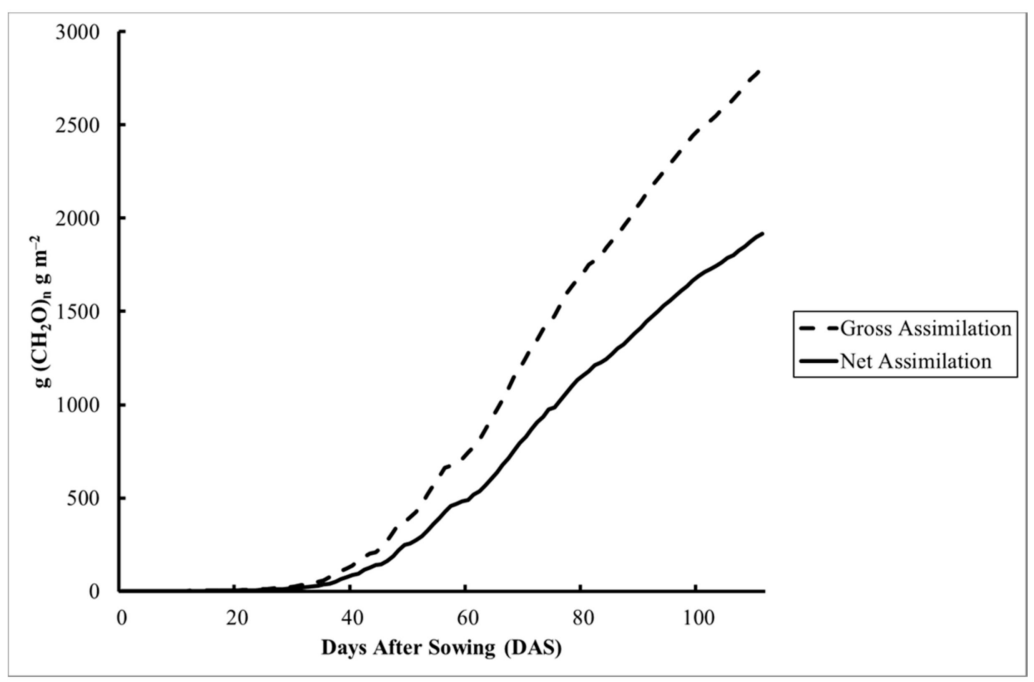

(b)

Figure 3. (a) Estimated daily gross and net assimilation for SIL05 sown early in 2012. (b) Estimated accumulation of gross and daily assimilation for SIL05 sown early in 2012.

Table 8. Simulated gross assimilation, respiration and net assimilation.

\begin{tabular}{|c|c|c|c|c|c|c|}
\hline Year & k & Sowing & Cultivar & $\begin{array}{l}\text { Gross Assimilation } \\
\mathrm{g}\left(\mathrm{CH}_{2} \mathrm{O}\right) \mathrm{n} \mathrm{m}^{-2}\end{array}$ & $\begin{array}{c}\text { Respiration } \\
\mathrm{g}\left(\mathrm{CH}_{2} \mathrm{O}\right) \mathrm{n} \mathrm{m}^{-2}\end{array}$ & 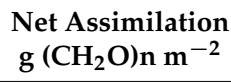 \\
\hline \multirow{12}{*}{2012} & \multirow{6}{*}{0.37} & \multirow{2}{*}{ Early } & SIL05 & 2808 & 890 & 1918 \\
\hline & & & FS501 & 3228 & 1022 & 2206 \\
\hline & & \multirow{2}{*}{ Medium } & SIL05 & 2758 & 857 & 1902 \\
\hline & & & FS501 & 3098 & 963 & 2136 \\
\hline & & \multirow{2}{*}{ Late } & SIL05 & 2657 & 821 & 1835 \\
\hline & & & FS501 & 3219 & 995 & 2224 \\
\hline & \multirow{6}{*}{0.60} & \multirow{2}{*}{ Early } & SIL05 & 3521 & 1117 & 2405 \\
\hline & & & FS501 & 3857 & 1222 & 2635 \\
\hline & & \multirow{2}{*}{ Medium } & SIL05 & 3464 & 1076 & 2389 \\
\hline & & & FS501 & 3689 & 1146 & 2543 \\
\hline & & \multirow{2}{*}{ Late } & SIL05 & 3233 & 1000 & 2233 \\
\hline & & & FS501 & 3806 & 1177 & 2629 \\
\hline \multirow{8}{*}{2013} & \multirow{4}{*}{0.37} & \multirow{2}{*}{ Early } & SIL05 & 2681 & 842 & 1840 \\
\hline & & & FS501 & 3400 & 1075 & 2326 \\
\hline & & \multirow{2}{*}{ Medium } & SIL05 & 2347 & 738 & 1609 \\
\hline & & & FS501 & 3433 & 1088 & 2345 \\
\hline & \multirow{4}{*}{0.60} & \multirow{2}{*}{ Early } & SIL05 & 3209 & 1011 & 2199 \\
\hline & & & FS501 & 3888 & 1231 & 2657 \\
\hline & & \multirow{2}{*}{ Medium } & SIL05 & 2996 & 944 & 2052 \\
\hline & & & FS501 & 3858 & 1226 & 2632 \\
\hline
\end{tabular}




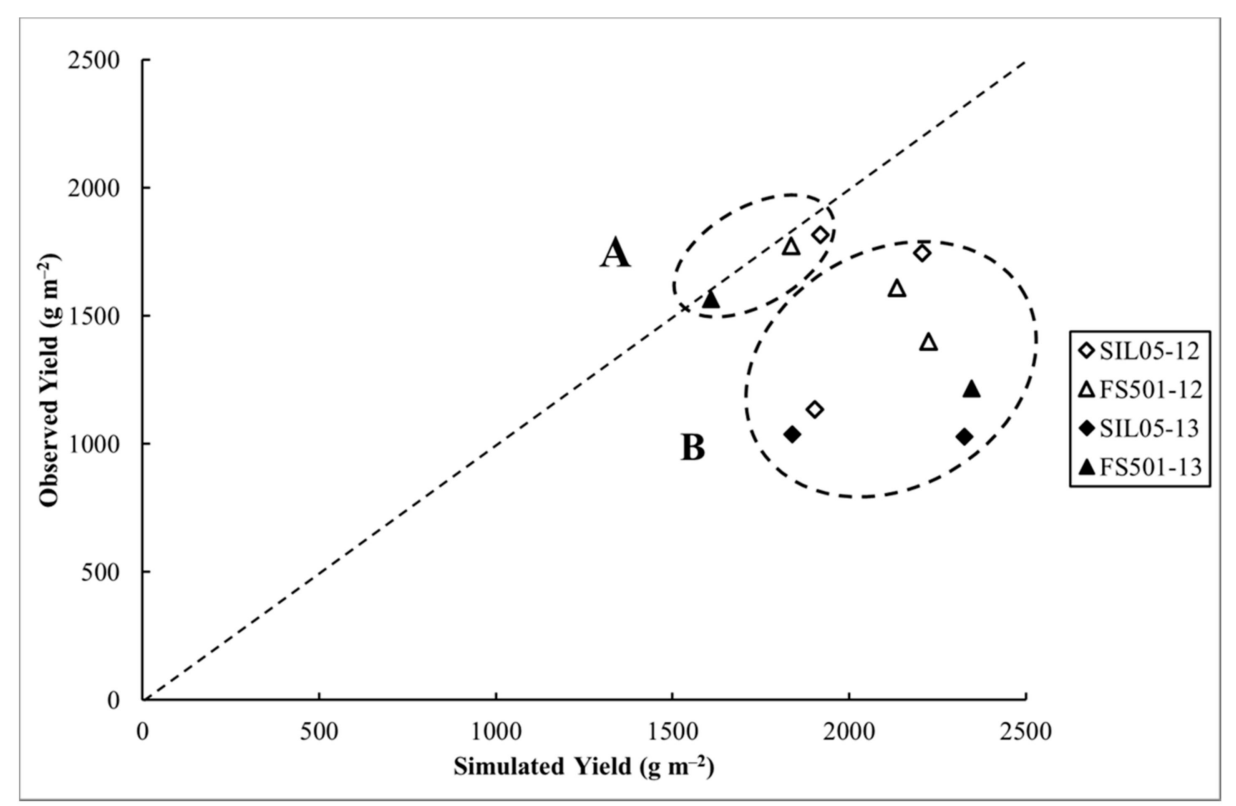

Figure 4. Comparison between simulated and observed yield: (A) the plots where the simulated yield was close to the observed yield; and (B) the plots where the simulated yield was higher than the observed yield.

\subsection{Estimation of Ethanol Yield}

Ethanol yield was estimated using stem yield and brix obtained in the present study following methodologies from the literature $[20,25,41]$ (Table 10). Estimated ethanol production exceeded $2000 \mathrm{~L} \mathrm{ha}^{-1}$ for SIL05 and FS501 with early sowing as well as SIL05 with medium sowing in 2014. With late sowing in 2014 and early and medium sowing in 2015, estimated ethanol production was generally low. 
Table 9. Estimation of biomass production of sorghum from solar radiation and rainfall.

\begin{tabular}{|c|c|c|c|c|c|c|c|c|c|c|}
\hline \multirow[t]{2}{*}{ Region/Country } & \multirow{2}{*}{ Location } & \multirow{2}{*}{$\begin{array}{l}\text { Latitude } \\
\left({ }^{\circ} \mathrm{N}\right)\end{array}$} & \multicolumn{3}{|c|}{ Year } & \multirow{2}{*}{$\begin{array}{c}\text { Temperature } \\
\left({ }^{\circ} \mathrm{C}\right)\end{array}$} & \multirow{2}{*}{$\begin{array}{l}\text { Radiation } \\
\left(\mathrm{MJ} \mathrm{m}^{-2}\right)\end{array}$} & \multirow{2}{*}{$\begin{array}{l}\text { Rainfall } \\
(\mathrm{mm})\end{array}$} & \multicolumn{2}{|c|}{$\begin{array}{l}\text { Estimated Biomass } \\
\text { Production }\left(\mathrm{Mg} \mathrm{ha}^{-1}\right)\end{array}$} \\
\hline & & & Temperature & Radiation & Rainfall & & & & Radiation & Rainfall \\
\hline \multirow{6}{*}{ the Kanto region } & Tsukuba (Kannondai) & 36.02 & \multirow{2}{*}{\multicolumn{3}{|c|}{$\begin{array}{l}2012 \\
2013\end{array}$}} & 23.0 & 2867 & 633 & 40.1 & 31.7 \\
\hline & & & & & & 22.9 & 2842 & 417 & 39.8 & 20.8 \\
\hline & Tsukuba (Tateno) & 36.03 & \multicolumn{3}{|c|}{$1981-2010^{+}$} & $21.7^{\dagger}$ & $2418^{+}$ & $694^{+}$ & 33.8 & 34.7 \\
\hline & Utsunomiya & 36.33 & \multirow{2}{*}{\multicolumn{3}{|c|}{$\begin{array}{l}1981-2010^{+} \\
1981-2010^{+}\end{array}$}} & $21.9^{\dagger}$ & $2181^{\dagger}$ & $957^{+}$ & 30.5 & 47.9 \\
\hline & Choshi & 35.44 & \multirow{2}{*}{\multicolumn{3}{|c|}{$\begin{array}{l}1981-2010^{+} \\
1981-2010^{+}\end{array}$}} & $21.5^{\dagger}$ & $2599^{+}$ & $751^{+}$ & 36.4 & 37.5 \\
\hline & Tokyo & 35.41 & & & & $23.6^{+}$ & $2179^{+}$ & $837^{+}$ & 30.5 & 41.9 \\
\hline the Shikoku region & Takamatsu & 34.20 & \multicolumn{3}{|c|}{$1981-2010^{+}$} & $24.3^{\dagger}$ & $2653^{+}$ & $637^{+}$ & 37.1 & 31.9 \\
\hline the Nansei region & Naha & 26.13 & \multicolumn{3}{|c|}{$1981-2010^{+}$} & $27.2^{\dagger}$ & $2795^{+}$ & $1122^{+}$ & 39.1 & 56.1 \\
\hline \multirow{3}{*}{ USA } & Nebraska & 41.98 & $1961-19$ & & $2007-2008^{a}$ & $20.3 \ddagger$ & $3229 \ddagger$ & $245-563^{a}$ & 45.2 & $12.3-28.2$ \\
\hline & Illinois & 39.83 & $1961-19$ & & $2009-2010^{\mathrm{b}}$ & $21.5^{\ddagger}$ & $3151 \ddagger$ & $307-876^{\mathrm{b}}$ & 44.1 & $15.4-43.8$ \\
\hline & Louisiana & 30.53 & $1961-19$ & & $2010-2011^{c}$ & $26.4 \ddagger$ & $2964 \ddagger$ & $357-727^{c}$ & 41.5 & $17.9-36.4$ \\
\hline
\end{tabular}

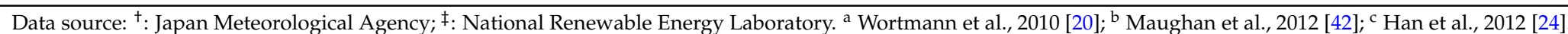

Table 10. Estimation of ethanol yield and production by three methods.

\begin{tabular}{|c|c|c|c|c|c|c|c|c|}
\hline \multirow[b]{2}{*}{ Year } & \multirow[b]{2}{*}{ Sowing } & \multirow[b]{2}{*}{ Cultivar } & \multicolumn{2}{|c|}{ Wortmann et al. (2010) [20] } & \multicolumn{2}{|c|}{ Zhao et al. (2012) [25] } & \multicolumn{2}{|c|}{ Okinawa General Bureau (2010) [41] } \\
\hline & & & $\begin{array}{l}\text { Ethanol Yield } \\
\left(\mathrm{L} \mathrm{Mg}^{-1} \mathrm{FS} *\right)\end{array}$ & $\begin{array}{l}\text { Ethanol Production } \\
\left(\mathrm{L} \mathrm{ha}^{-1}\right)\end{array}$ & $\begin{array}{l}\text { Ethanol Yield } \\
\left(\mathrm{L} \mathrm{Mg}^{-1} \mathrm{FS}{ }^{*}\right)\end{array}$ & $\begin{array}{l}\text { Ethanol Production } \\
\left(\mathrm{L} \mathrm{ha}^{-1}\right)\end{array}$ & $\begin{array}{l}\text { Ethanol Yield } \\
\left(\mathrm{L} \mathrm{Mg}^{-1} \mathrm{FS}{ }^{*}\right) \\
\end{array}$ & $\begin{array}{c}\text { Ethanol Production } \\
\left(\mathrm{L} \mathrm{ha}^{-1}\right)\end{array}$ \\
\hline \multirow{6}{*}{2012} & \multirow{2}{*}{ Early } & SIL05 & $42-44$ & $2421-2970$ & $34-35$ & 1958-2333 & $35-36$ & $2033-2421$ \\
\hline & & FS501 & $45-49$ & $2187-2458$ & $36-39$ & 1770-1934 & $38-40$ & 183-2008 \\
\hline & \multirow{2}{*}{ Medium } & SIL05 & 56 & $1015-3487$ & $43-46$ & $827-2712$ & $45-47$ & $859-2815$ \\
\hline & & FS501 & $17-24$ & $901-1404$ & $14-20$ & $707-1139$ & $14-20$ & $734-1182$ \\
\hline & \multirow{2}{*}{ Late } & SIL05 & $40-52$ & 1631-1997 & $31-40$ & $1275-1552$ & $32-42$ & $1323-1612$ \\
\hline & & FS501 & $15-22$ & $690-1365$ & $12-17$ & $540-1049$ & $12-17$ & $561-1089$ \\
\hline \multirow{4}{*}{2013} & \multirow{2}{*}{ Early } & SIL05 & $15-22$ & $782-818$ & $12-17$ & $602-639$ & $12-18$ & $625-663$ \\
\hline & & FS501 & $11-12$ & 712-801 & $8-10$ & $553-626$ & $9-10$ & $574-650$ \\
\hline & \multirow{2}{*}{ Medium } & SIL05 & $24-42$ & $804-1871$ & $20-33$ & 661-1455 & $20-341$ & $686-1511$ \\
\hline & & FS501 & $15-27$ & $1041-1141$ & $12-20$ & $762-895$ & $2-21$ & $791-929$ \\
\hline
\end{tabular}

* Fresh stalks. 


\section{Discussion}

\subsection{Yield and Brix}

As mentioned in the Introduction, Inuyama et al. [27] obtained stem weights of sorghum in the range of $3.37-4.48 \mathrm{~kg} \mathrm{~m}^{-2}$ on a fresh matter basis. These values are comparable to the lower range of the values obtained in the present study, i.e., $3.35-7.56 \mathrm{~kg} \mathrm{~m}^{-2}$. To compare yield levels obtained in the present study in terms of those reported by other workers, DM yield was plotted against DM content (Figure 5a,b) [20,43,44]. Compared on a DM basis, yields obtained in the present study were relatively lower than those reported by Wortmann et al. [20] (Figure 5a) and Fukazawa et al. (Figure 5b) [43], while they were comparable to those reported by Harada et al. (Figure 5b) [44]. High values of DM content reported by Wortmann et al. [20] and Fukazawa et al. [43] appeared to explain at least partly the differences in DM yield between their studies and the present study (Figure 5a). As to stem brix, Kamiyama et al. [45] observed values in the range of $13.7 \%$ to $16.2 \%$ for three cultivars in Ibaraki prefecture, while stem brix in the present study and especially of FS501 was generally lower. Kawahigashi et al. [46] reported brix values ranging from $2.8 \%$ to $19.6 \%$ for 109 sorghum accessions where SIL05 showed a value as high as $19.4 \%$ compared to the range of $5.3 \%$ to $16.2 \%$ observed in the present study for the same cultivar. When plotted against DM content, stem brix was positively correlated to DM content (Figure 5c) [20,43], which was in accordance with Table 6.

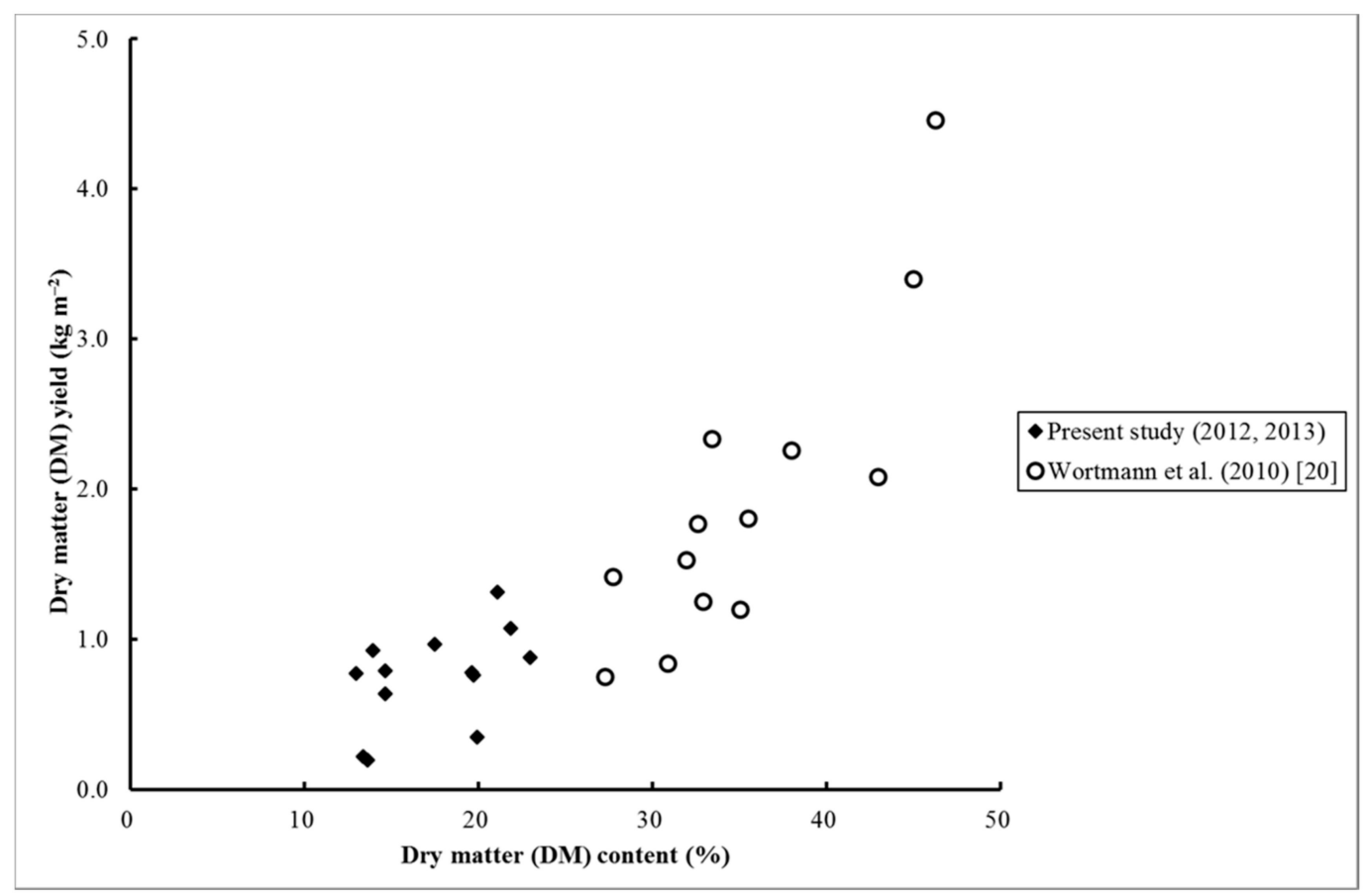

(a)

Figure 5. Cont. 


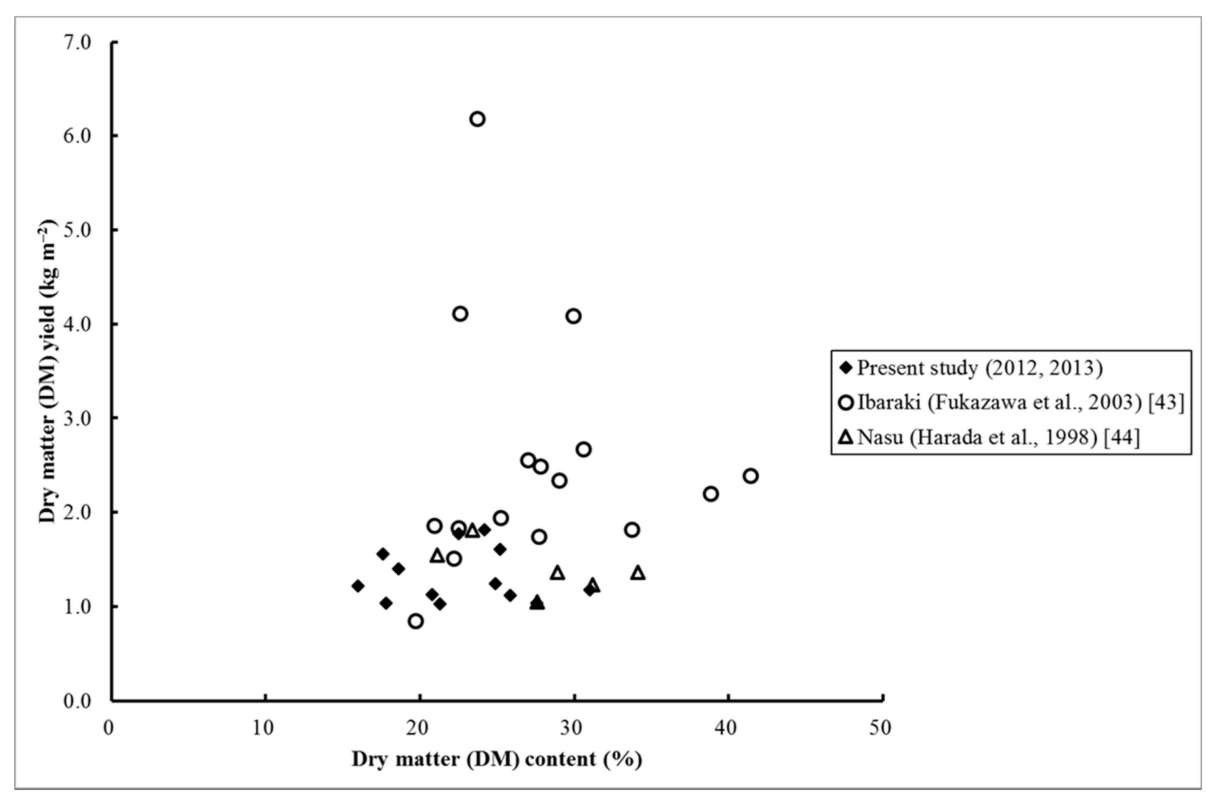

(b)

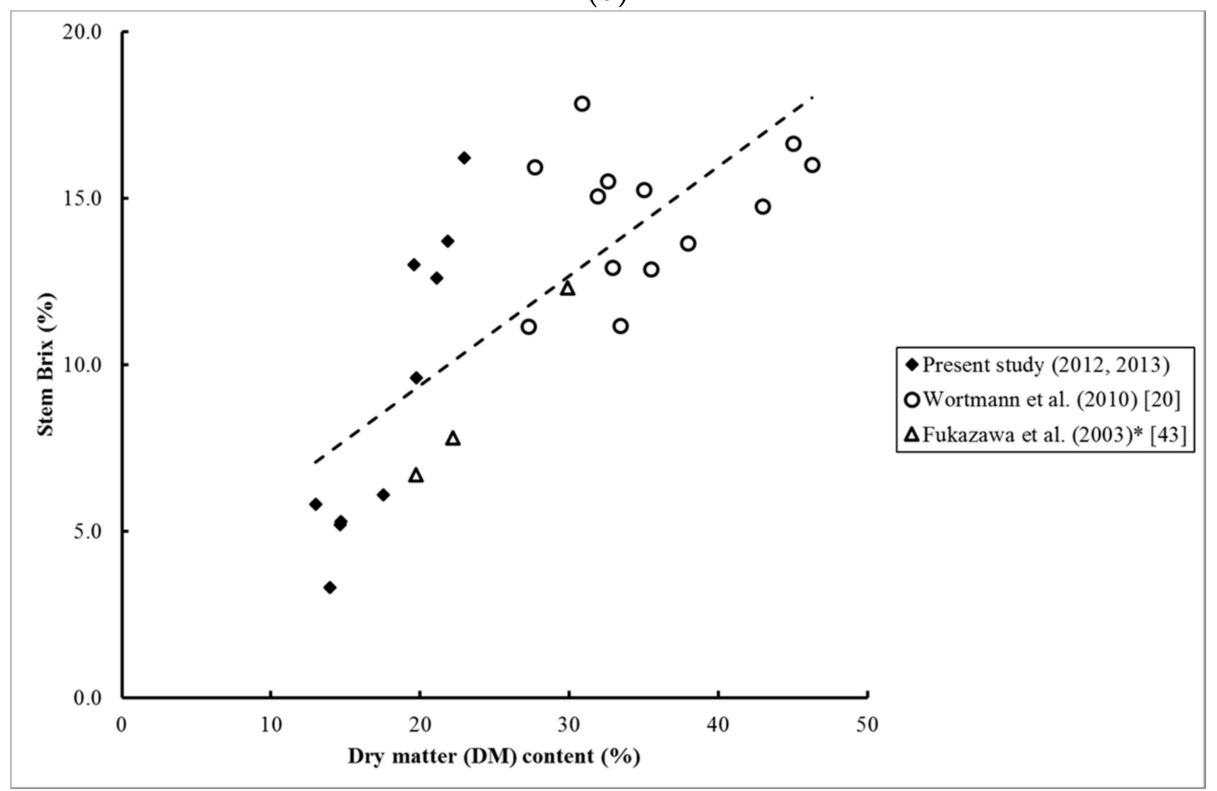

(c)

Figure 5. (a) The relationship between stem dry matter (DM) content and stem DM yield. (b) The relationship between above-ground DM content and above-ground DM yield. (c) The relationship between stem DM content and stem brix. * The relationship between above-ground DM content and stem brix.

\subsection{RUE}

RUE estimated in the present study was in the range of $1.01-1.58 \mathrm{~g} \mathrm{MJ}^{-1}$ solar and $0.85-1.27 \mathrm{~g} \mathrm{MJ}^{-1}$ solar for light extinction coefficient of 0.37 and 0.60 , respectively. In the case of 8080 , leaves are arranged along a short statue, while the number of leaves is not very different from that of SIL05 and FS501. This might explain the smaller RUE obtained with 8080 compared to other cultivars. Monteith [47] pointed out that at least during the vegetative stage, the relationship between intercepted radiation and the annual production of DM was surprisingly similar for barley, potatoes, sugar beet and apples and showed that the slope, RUE, would be approximately $1.4 \mathrm{~g} \mathrm{MJ}^{-1}$ solar in the UK. Values between 1.10 and $2.16 \mathrm{~g} \mathrm{MJ}^{-1}$ solar have been cited for sorghum [48]. Hammer et al. [36] obtained RUE in the 
range of 1.19-1.84 $\mathrm{g} \mathrm{MJ}^{-1}$ solar for dwarf sorghum. Horie and Okada [49] reported RUE of $2.75 \mathrm{~g} \mathrm{MJ}^{-1}$ PAR (Photosynthetically Active Radiation) with rice until maturation. Their calculation, however, included root biomass, which was not assessed in the present study. In a recent study with sorghum in Northern Italy $\left(44^{\circ} 32^{\prime} \mathrm{N}, 11^{\circ} 11^{\prime} \mathrm{E}, 38 \mathrm{~m}\right.$ a.s.l.), Ceotto et al. [37] obtained RUE of as high as $3.48 \mathrm{~g}$ $\mathrm{MJ}^{-1}$ PAR where above-ground DM yield was plotted against intercepted PAR. Similarly in Kansas State, USA $\left(39^{\circ} 24^{\prime} \mathrm{N}, 101^{\circ} 4^{\prime} \mathrm{W}, 963 \mathrm{~m}\right.$ a.s.l.), Narayanan et al. [40] obtained RUE in the range of 2.13 to $3.53 \mathrm{~g} \mathrm{MJ}^{-1}$ PAR. Values of $1.4 \mathrm{~g} \mathrm{MJ}^{-1}$ solar and $2.0 \mathrm{~g} \mathrm{MJ}^{-1}$ solar were reported [50] for C3 and C4 species, respectively, grown under optimum conditions. Bearing these values in mind, RUE obtained in the present study was considered relatively low for sorghum suggesting room for improvement in cultivation.

\subsection{Estimation of Potential Yield and Ethanol Yield}

An attempt was made to simulate potential yield of sorghum in the present study. As the LAI data set used was the one obtained in the present study, one needs to be aware that potential yield here means the one restricted by the observed LAI. The observed yields were found to be below the simulated yields especially in 2013 implying that the photosynthetic ability of green leaves was likely to be impaired to some extent. Possible factors we can think of are limited precipitation as well as the infestation by aphids. Pronounced effects of both factors such as rolling of leaves and leaves covered by black sooty mold on the aphid honey dew were observed especially in 2013. The LAI values observed in their peak in the present study appeared comparable to or even greater than the values reported by Narayanan et al. [40], which is interesting considering that some of the genotypes in their study produced above-ground DM yield greater than $2000 \mathrm{~g} \mathrm{~m}^{-2}$. It should be noted that in the present study, estimation was conducted in a quite simplified manner without differentiating the vegetative phase from the reproductive phase. Besides, respiratory costs associated with sugar accumulation in the stem during the later phase of growth could complicate the balance sheet of assimilates in sorghum, in a similar way to sugarcane. In Table 9, a simple estimation of potential DM yield from weather data was attempted to evaluate the climatic resources of different places to produce sorghum. Solely from the perspective of solar radiation, one might be able to expect production of 30 to $40 \mathrm{Mg} \mathrm{ha}^{-1}$ of biomass yield in the Kanto region, a slightly lower level compared to that in USA, although it would be very much influenced by precipitation during the growth period. Both in 2012 and 2013 of the present study, potential yield was suppressed greatly by the amount of rainfall. In 2013 in particular, only a half of production estimated from solar radiation was considered to be theoretically possible. The issue of dry summer experienced in the study area will be further discussed later. As brix was generally low in the present study, the potential ethanol yield was low compared to the values reported in the literature [20,25].

\subsection{Implication for Field Management}

\subsubsection{Seed Rates and Weeds Infestation}

It was possible to reduce the amount of sorghum seeds needed for sowing by $80-90 \%$ using a pneumatic seeder. A small plot experiment conducted in 2013 (data not shown), however, indicated that the use of a power harrow seeder might be a better way of sowing sorghum in terms of early crop growth and increased competition with weeds for resources even though one needs more seeds with this machinery. The issue of crop establishment requires further examination. Digitaria (Digitaria ciliaris (Retz.) Koel.), spotted lady's-thumb (Persicaria maculosa Gray), white goosefoot (Chenopodium album L.), and Amaranthus retroflexus (Amaranthus viridis L.) dominated some of the plots and appeared to have affected the growth and yield of sorghum in both years (data not shown). When sown in the middle of May, it took a week for sorghum seeds to germinate compared to $4-5$ days in June. This, combined with slow growth of sorghum during the early growth phase which is sometimes compared with maize [51], is likely to allow weeds to establish faster than the crop. Sorghum originates from 
semi-arid tropics [52] and one cannot deny that temperature in the Kanto region is too low to exploit the yielding ability of this crop to its full capacity. Low temperature during the early phase of growth up to canopy establishment, a similar situation with sugarcane in southwest islands [53,54], is one of the main factors limiting yields. It appears that, in this region, when sowing sorghum as early as the middle of May, a cultivar possessing the trait of faster early phase growth would be required to compete effectively with weeds.

\subsubsection{Aphids}

Aphids were present in both years. In 2013, an outbreak was observed from early August until late August when it was stopped with the event of rainfall. Setokuchi [55] pointed out that dry weather and high temperature are the factors that favor growth of aphids (Longiunguis sacchari (Zehntner)). He reported a reduced DM content of sorghum following the infestation by this pest. As previously mentioned, values of DM content in the present study were found to be generally low compared with those reported in other studies. As a positive correlation was observed between DM content and stem brix, it is possible that stem brix was negatively affected by the presence of aphids. When one looks at mean temperature over last 30 years [56], maximum temperature in August in Tsukuba is lower by approximately $2{ }^{\circ} \mathrm{C}$ than that in Tadotsu, Kagawa, a prefecture known within Japan for its hot and dry summers. Similarly, the amount of rainfall during summer in Tsukuba is greater than that in Tadotsu. Weather data in 2012 and 2013 [56] however tell us a different story. There was almost no difference between the two locations in maximum temperature, while precipitation in summer was less in Tsukuba than in Tadotsu indicating that the weather conditions in Tsukuba were more likely to favor aphids. Evidence from the present study suggests that it is important to control aphids in sorghum during this growth phase and that the aspect of aphids needs to be investigated further, as this could be one of the major issues affecting the successful cultivation of sorghum in the Kanto region.

\subsubsection{Typhoons}

In 2012, two typhoons affected the field experiment. The first one was in June and only caused some leaf damage. High ridging was considered to have saved the seedlings from lodging. The second typhoon was at the end of September, and almost completely knocked down the cultivars of more than $3 \mathrm{~m}$ in height. i.e., SIL05 and FS501. The number of typhoons that have come close to the Kanto region in last 20 years is much fewer than to Okinawa, one of the most vulnerable regions to typhoons in the country (Figure 6) [56], however, it is probably optimistic to expect no typhoons to affect the Kanto region during the period from May to September. From the perspective of minimizing the risk of lodging, it is preferable that sorghum of a high growth habit be harvested by early September. In this respect, it might be better to place sorghum of a shorter growth habit such as 8080 , which survived the typhoon at the end of September, after wheat or barley in the sequence of crop rotation, as harvesting wheat and barley would occur usually in June in this part of the world.

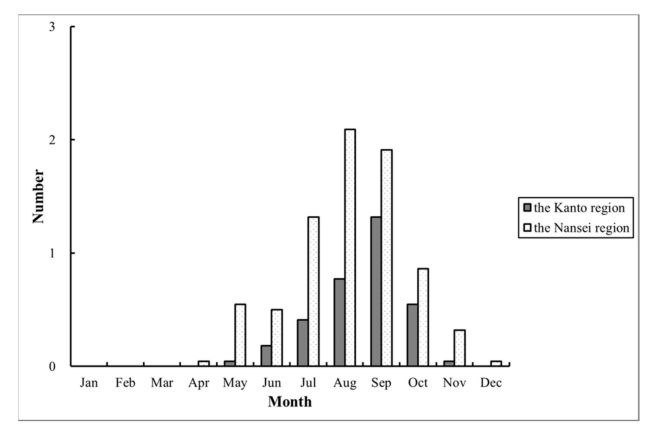

Figure 6. The average number of typhoons that had come close to the Kanto and the Nansei region in last 20 years. 


\subsubsection{Future Perspective}

Other issues to be looked into are the nutrient management of sorghum for biomass usage as well as preservation of the crop. As to the former issue, excess nitrate accumulation in feed crops including sorghum [44], very often being the consequence of overdosed fertilizer and/or manure application [57], has been regarded as a factor that can cause serious health problems with livestock. However, fertilizer recommendation rates for feed sorghum vary for prefectures with the differences sometimes exceeding twofold [58]. It is of importance therefore, from the perspective of nutrient recycling and energy saving [22], that the wastes from the neighboring ethanol plants such as vinasse should be utilized as crop fertilizers. The latter issue of preservation is worth studying, because the stem juice of sorghum is known to deteriorate rather quickly after harvest [59], which is a possible factor that could hinder the use of sorghum as a feedstock. In addition, in the view of completing the cropping system as a whole, the inclusion of high yielding winter crops [60] would be an essential component to be considered in future studies. Poor early growth observed with the plots sown on 13 May, 2013 was considered to be at least partly attributable to possible allelopathic effects of oat residues [61] especially roots [62] as all the above-ground parts of oat had been removed from the field prior to sowing sorghum. Sown after oat as well, early growth of sorghum sown on 28 May 2013 did not appear to have been affected by the previous crop to the extent observed with the crop sown two weeks earlier. The issue of allelopathy would probably require a further examination to establish cropping systems that could support sustainable biomass production in the target region. Maize cultivation could be a possible alternative to avoid continuous sorghum cropping. A large part of the issues discussed above could probably not be solved solely by improving agronomy. Multiple cultivars are required if one wants to run any cropping system in sustainable manner. To cultivate sorghum in the Kanto region especially within a global warming context, more cultivars, for example, preferably with early vigor and equipped with resistance to aphids need to be developed.

\section{Conclusions}

Sorghum seeds of both sweet sorghum (SIL05 and FS501) and grain sorghum (8080) cultivars were sown under two field experiments conducted in 2012 and 2013 to estimate yielding ability of this crop in the Kanto region in the context of bioethanol production. Above-ground DM yield in the range of $1.03-1.82 \mathrm{~kg} \mathrm{~m}^{-2}, 1.22-1.77 \mathrm{~kg} \mathrm{~m}^{-2}$ and $0.70-1.18 \mathrm{~kg} \mathrm{~m}^{-2}$ were obtained for SIL05, FS501 and 8080 , respectively, in two years. The yield level obtained in the present study was found below the estimated potential except for in a few cases. In contrast to USA, potential biomass production was greater when estimated from rainfall than from radiation in most of the locations in Japan. Observed yields, however, were greatly suppressed by the amount of rainfall in both experimental seasons in the study site. As brix was generally low in the present study, the potential ethanol yield was low compared to the values reported in the literature. A positive correlation observed between DM content and stem brix suggests a possibility that stem brix was negatively affected by the presence of aphids. Controlling the population of aphids was identified to be one of the crucial factors determining the successful cultivation of sorghum in the Kanto region.

Acknowledgments: The present study was conducted as a part of the biomass project, "Development of Technologies for Biofuel Production Systems in Rural Areas (2012-2015)" funded by Ministry of Agriculture and Forestry and Fisheries. The authors would like to mention that this study would not have been possible without the support of field and laboratory technicians: Hiroo Sato, Toshichika Ishii, Masahiko Yamazaki, Toshihiro Suzuki, Masaki Irie, Hirokazu Kamikihara and Haruko Ohno. We thank Tomoyuki Takai at Kyushu Okinawa Agricultural Research Center for kindly providing us with seeds of SIL05. Our special thanks are due to Martin C. Hare of Harper Adams University for valuable comments to the manuscript.

Author Contributions: Shoko Ishikawa and Ken-ichi Yakushido conceived and designed the experiments; Shoko Ishikawa, Takayuki Tsukamoto, Hitoshi Kato and Kazuto Shigeta performed the experiments; Shoko Ishikawa analyzed the data; Shoko Ishikawa contributed reagents/materials/analysis tools; and Shoko Ishikawa wrote the paper. 
Conflicts of Interest: The present study was conducted as a part of the biomass project, "Development of Technologies for Biofuel Production Systems in Rural Areas (2012-2015)" funded by Ministry of Agriculture and Forestry and Fisheries. The founding sponsors had no role in the design of the study; in the collection, analyses, or interpretation of data; in the writing of the manuscript, and in the decision to publish the results. The authors declare no conflict of interest.

\section{References}

1. Nakashima, T.; Ishikawa, S. Energy inputs and greenhouse gas emissions associated with small-scale farmer sugarcane cropping systems and subsequent bioethanol production in Japan. NJAS Wagen. J. Life Sci. 2016, 76, 43-53. [CrossRef]

2. Saga, K.; Imou, K.; Yokoyama, S.; Fujimoto, S.; Yanagida, T.; Minowa, T. Study on rice straw collection system for bioethanol production. J. Jpn. Soc. Energy Resour. 2008, 29, 8-13.

3. Kanai, G.; Takekura, K.; Kato, H.; Kobayashi, Y.; Yakushido, K. Effect of biomass collection-center location on transportation efficiency (Part 2)-Examining the route length using GIS. J. Soc. Agric. Struct. Jpn. 2011, 42, 65-72.

4. Park, J.; Shiroma, R.; Al-Haq, M.I.; Zhang, Y.; Ike, M.; Arai-Sanoh, Y.; Ida, A.; Kondo, M.; Tokuyasu, K. A novel lime pretreatment for subsequent bioethanol production from rice straw-Calcium capturing by carbonation (CaCCO) process. Bioresour. Technol. 2010, 101, 6805-6811. [CrossRef] [PubMed]

5. Shiroma, R.; Park, J.; Al-Haq, M.I.; Arakane, M.; Ike, M.; Tokuyasu, K. RT-CaCCO process: An improved $\mathrm{CaCCO}$ process for rice straw by its incorporation with a step of lime pretreatment at room temperature. Bioresour. Technol. 2011, 102, 2943-2949. [CrossRef] [PubMed]

6. Kramer, R.; Belanger, H. Fermentation-based biofuels. In Plant Biomass Conversion; Hood, E.E., Nelson, P., Powell, R., Eds.; Wiley-Blackwell: West Sussex, UK, 2011; pp. 255-274.

7. Wilkie, A.C.; Riedesel, K.J.; Owens, J.M. Stillage characterization and anaerobic treatment of ethanol stillage from conventional and cellulosic feedstocks. Biomass Bioenergy 2000, 19, 63-102. [CrossRef]

8. Janke, L.; Leite, A.F.; Batista, K.; Silva, W.; Nikolausz, M.; Nelles, M.; Stinner, W. Enhancing biogas production from vinasse in sugarcane biorefineries: Effects of urea and trace elements supplementation on process performance and stability. Bioresour. Technol. 2016, 217, 10-20. [CrossRef] [PubMed]

9. Tavella, C.M.; Verges, R.P.; Kohli, M.M. Progress in Development of Double Purpose Wheats in Uruguay. Available online: http://knowledgecenter.cimmyt.org/cgi-bin/koha/opac-detail.pl?biblionumber=3431\& shelfbrowse_itemnumber $=4497$ (accessed on 9 May 2017).

10. Moreira, J.R.; Goldemberg, J. The alcohol program. Energy Policy 1999, 27, 229-245. [CrossRef]

11. Butterbach-Bahl, K.; Kiese, R. Biofuel production on the margins. Nature 2013, 493, 483-485. [CrossRef] [PubMed]

12. Yoshida, T. Production and breeding of sorghum and pearl millet. Jpn. J. Crop Sci. 2002, 71, 147-153. [CrossRef]

13. Vasilakoglou, I.; Dhima, K.; Karagiannidis, N.; Gatsis, T. Sweet sorghum productivity for biofuels under increased soil salinity and reduced irrigation. Field Crops Res. 2011, 120, 38-46. [CrossRef]

14. Stewart, F.L. Sorghum and Its Products: An Account of Recent Investigations Concerning the Value of Sorghum in Sugar Production, Together with a Description of a New Method of Making Sugar and Refined Syrup from This Plant. Adapted to Common Use; J.B. Lippincott \& Co.: Philadelphia, PA, USA, 1867; p. 240.

15. Rooney, W.L. Sorghum improvement-Integrating traditional and new technology to produce improved genotypes. Adv. Agron. 2004, 83, 37-109.

16. Hoshikawa, K. Sweet sorghum as biomass. Agric. Hort. 1981, 56, 497-503.

17. Hoshikawa, K. Sweet sorghum as a hopeful biomass crop. JATAFF J. 1985, 8, 22-26.

18. Goto, Y.; Nakamura, S.; Sakai, K.; Hoshikawa, K. Analysis of elongation and thickening of internodes in sweet sorghum (Sorghum bicolor Moench). Jpn. J. Crop Sci. 1994, 63, 473-479. [CrossRef]

19. United Nations Framework Convention on Climate Change. Available online: https://unfccc.int/kyoto_ protocol/items/2830.php (accessed on 9 May 2017).

20. Wortmann, C.S.; Liska, A.J.; Ferguson, R.B.; Lyon, D.J.; Klein, R.N.; Dweikat, I. Dryland performance of sweet sorghum and grain crops for biofuel in Nebraska. Agron. J. 2010, 102, 319-326. [CrossRef]

21. Goff, B.M.; Moore, K.J.; Fales, S.L.; Heaton, E.A. Double-cropping sorghum for biomass. Agron. J. 2010, 102, 1586-1592. [CrossRef] 
22. Anfinrud, R.; Cihacek, L.; Johnson, B.L.; Ji, Y.; Berti, M.T. Sorghum and kenaf biomass yield and quality response to nitrogen fertilization in the Northern Great Plains of the USA. Ind. Crop Prod. 2013, 50, 159-165. [CrossRef]

23. Erickson, J.E.; Helsel, Z.R.; Woodard, K.R.; Vendramini, M.B.; Wang, Y.; Sollenberger, L.E.; Gilbert, R.A. Planting date affects biomass and brix of sweet sorghum grown for biofuel across Florida. Agron. J. 2011, 103, 1827-1833. [CrossRef]

24. Han, K.J.; Alison, M.W.; Pitman, W.D.; Day, D.F.; Kim, M.; Madsen, L. Planting date and harvest maturity impact on biofuel feedstock productivity and quality of sweet sorghum grown under temperate Louisiana conditions. Agron. J. 2012, 104, 1618-1624. [CrossRef]

25. Zhao, Y.L.; Steinberger, Y.; Shi, M.; Han, L.P.; Xie, G.H. Changes in stem composition and harvested produce of sweet sorghum during the period from maturity to a sequence of delayed harvest dates. Biomass Bioenergy 2012, 39, 261-273. [CrossRef]

26. Xuan, T.D.; Phuong, N.T.; Khang, D.T.; Khanh, T.D. Influence of sowing times, densities, and soils to biomass and ethanol yield of sweet sorghum. Sustainability 2015, 7, 11657-11678. [CrossRef]

27. Inuyama, S.; Kaneko, K.; Ogihara, H. Sweet sorghum production in Kanto district of Japan. Res. Rep. Biomass Convers. Program 1988, 10, 51-58.

28. Tateno, K.; Ojima, M. Growth analysis of grain sorghum as affected by planting density and amount of nitrogen. Proc. Crop Sci. Soc. Jpn. 1973, 42, 555-559. [CrossRef]

29. Inuyama, S. Effect of the amount of irrigation water on growth and grain yield of grain sorghum. Jpn. J. Crop Sci. 1980, 49, 226-231. [CrossRef]

30. Hoshikawa, K.; Nakamura, S.; Goto, Y.; Tanaka, M.; Kabeya, Y. Relationships between changes in the heading date and yield-related traits of sweet sorghum (Sorghum bicolor Moench) in the northern area of Japan. Jpn. J. Crop Sci. 1994, 63, 610-615. [CrossRef]

31. Nakamura, S.; Goto, Y.; Hoshikawa, K. Analysis of yield production process in sweet sorghum (Sorghum bicolor Moench). I. Elongation patterns of leaf blade, leaf sheath and elongated internode. Jpn. J. Crop Sci. 1995, 64, 43-49. [CrossRef]

32. Wu, L.; Gau, M.; Takai, T.; Kasuga, S.; Yun, M.; Tokuyasu, K. Sorghum as whole-crop feedstock for integrated production of fermentable sugars. Ind. Crop Prod. 2013, 49, 645-647. [CrossRef]

33. Yasui, K. Soluble solid and sugar contents in the pressed juice of stalk of sweet sorghum [Sorghum bicolor (L.) Moench] as influenced by cultivar, seeding and harvesting time. Rep. Natl. Food Res. Inst. 1985, 46, 1-8.

34. Yasui, K. Soluble solid and sugar contents in the pressed juice of stalk of sweet sorghum [Sorghum bicolor (L.) Moench] as affected by planting density and manuring. Rep. Natl. Food Res. Inst. 1985, 47, 11-15.

35. Monsi, M.; Saeki, T. Über den Lichtfaktor in den Pflanzengesellschaften und seine Bedeutung für die Stoffproduktion. Jpn. J. Bot. 1953, 14, 22-52.

36. Hammer, G.L.; Van Oosterom, E.; McLean, G.; Chapman, S.C.; Broad, I.; Harland, P.; Muchow, R.C. Adapting APSIM to model the physiology and genetics of complex adaptive traits in field crops. J. Exp. Bot. 2010, 61, 2185-2202. [CrossRef] [PubMed]

37. Ceotte, E.; Di Candilo, M.; Castelli, F.; Badeck, F.W.; Rizza, F.; Soave, C.; Volta, A.; Villani, G.; Marletto, V. Comparing solar radiation interception and use efficiency for the energy crops giant reed (Arundo donax L.) and sweet sorghum (Sorghum bicolor L. Moench). Field Crops Res. 2013, 149, 159-166. [CrossRef]

38. Lövenstein, H.; Lantinga, E.A.; Rabbinge, R.; Van Keulen, H. Principles of Production Ecology; Department of Theoretical Production Ecology, Wageningen Agricultural University: Wageningen, The Netherlands, 1995; p. 121.

39. Hirose, T. Development of the Monsi-Saeki theory on canopy structure and function. Ann. Bot. 2005, 95, 483-494. [CrossRef] [PubMed]

40. Narayanan, S.; Aiken, R.M.; Prasad, P.V.V.; Xin, Z.; Yu, J. Water and radiation use efficiencies in sorghum. Agron. J. 2013, 105, 649-657. [CrossRef]

41. Okinawa General Bureau. Available online: http://www.ogb.go.jp/nousui/kankyo/8169/007568.html (accessed on 9 May 2017).

42. Maughan, M.; Voigt, T.; Parrish, A.; Bollero, G.; Rooney, W.; Lee, D.K. Forage and energy sorghum responses to nitrogen fertilization in Central and Southern Illinois. Agron J. 2012, 104, 1032-1040.

43. Fukazawa, Y.; Yoshio, T.; Tsuda, K. Characteristics of sorghum (Sorghum bicolor Moench.) cultivars. Bull. Ibaraki Pref. Livest. Res. Cent. 2003, 35, 15-20. 
44. Harada, H.; Sunaga, Y.; Hatanaka, T. Variety difference of nitrate nitrogen concentration of sorghum under a large amount of nitrogen fertilizer application. Grassl. Sci. 1998, 43, 449-451.

45. Kamiyama, A.; Yoji, N.; Homma, T.; Umehara, R.; Kobayashi, R.; Matsuda, T.; Nakamura, S.; Goto, Y.; Inoue, E.; Narisawa, K.; et al. Effect of weather condition on sugar yield in sweet sorghum (Sorghum bicolor (L.) Moench) stem. Tohoku J. Crop Sci. 2009, 52, 39-40.

46. Kawahigashi, H.; Kasuga, S.; Okuizumi, H.; Hiradate, S.; Yonemaru, J. Evaluation of Brix and sugar content in stem juice from sorghum varieties. Grassl. Sci. 2013, 59, 11-19. [CrossRef]

47. Monteith, J.L. Climate and the efficiency of crop production in Britain. Philos. Trans. R. Soc. Lond. B 1977, 281, 277-294. [CrossRef]

48. Sinclair, T.R.; Muchow, R.C. Radiation use efficiency. Adv. Agron. 1999, 65, 215-265.

49. Horie, T.; Okada, M. Development of modeling procedure for evaluating biomass resources in a cultivated field. Res. Rep. Biomass Convers. Program 1986, 2, 18-26.

50. Monteith, J.L. A reassessment of maximum growth rates for C3 and C4 crops. Exp. Agric. 1978, 14, 1-5. [CrossRef]

51. Kihara, Y.; Nemoto, K.; Suzuki, H.; Kaketa, M. Studies on mixed cropping of corn and sorghum. Bull. Kanagawa Livest. Exp. Stat. 1991, 81, 20-31.

52. Hoshikawa, K. Saibai shokubutsu No Kigen to Denpa. Available online: https://www.amazon.com/Saibaishokubutsu-no-kigen-denpa/dp/4817600721 (accessed on 9 May 2017).

53. Terauchi, T.; Nakagawa, H.; Matsuoka, M.; Nakano, H.; Sugimoto, A. Comparison of the early growth between sugarcane and sweet sorghum. Jpn. J. Crop Sci. 1999, 68, 414-418. [CrossRef]

54. Ishikawa, S.; Terauchi, T.; Sakaigaichi, T.; Hattori, T.; Matsuoka, M.; Ujihara, K.; Irei, S.; Terajima, Y.; Sugimoto, A.; Komaki, Y.; et al. New Early Maturing Sugarcane 'KN00-114'. Bull. NARO Kyushu Okinawa Agric. Res. Cent. (NARO/KARC) 2014, 61, 1-16.

55. Setokuchi, O. Ecology of Longiunguis sacchari (ZEHTNER) (Homoptera: Aphididae). Bull. Kagoshima Agric. Exp. Stat. 1980, 8, 1-41.

56. Japan Meteorological Agency. Available online: http://www.data.jma.go.jp/obd/stats/etrn/index.php (accessed on 9 May 2017).

57. Ishikawa, S.; Ando, S.; Sakaigaichi, T.; Terajima, Y.; Matsuoka, M. Effects of high nitrogen application on the dry matter yield, nitrogen content and nitrate-N concentration of sugarcane. Soil Sci. Plant Nutr. 2009, 55, 485-495. [CrossRef]

58. MAFF. Available online: http://www.maff.go.jp/j/seisan/kankyo/hozen_type/h_sehi_kizyun/ (accessed on 9 May 2017).

59. Lingle, S.E.; Tew, T.L.; Rukavina, H.; Boykin, D.L. Post-harvest changes in sweet sorghum I: Brix and sugars. Bioenergy Res. 2012, 5, 158-167. [CrossRef]

60. Ishikawa, S.; Hare, M.C.; Kettlewell, P.S. Effects of strobilurin fungicide programmes and fertilizer nitrogen rates on winter wheat: Leaf area, dry matter yield and nitrogen yield. J. Agric. Sci. 2012, 150, 427-441. [CrossRef]

61. Grimmer, O.P.; Masiunas, J.B. The weed control potential of oat cultivars. HortTechnology 2005, 15, 140-144.

62. Wang, Y.; Wu, F.; Liu, S. Allelopathic effects of root exudates from wheat, oat and soybean on seed germination and growth of cucumber. Allelopath. J. 2009, 24, 103-112.

(C) 2017 by the authors. Licensee MDPI, Basel, Switzerland. This article is an open access article distributed under the terms and conditions of the Creative Commons Attribution (CC BY) license (http://creativecommons.org/licenses/by/4.0/). 